\title{
Coupling between angled-facet amplifiers and tapered lens-ended fibers
}

\author{
Wang, Zheng; Mikkelsen, Benny; Pedersen, Bo; Stubkjær, Kristian
}

Published in:

Journal of Lightwave Technology

Link to article, DOI:

$10.1109 / 50.64922$

Publication date:

1991

Document Version

Publisher's PDF, also known as Version of record

Link back to DTU Orbit

Citation (APA):

Wang, Z., Mikkelsen, B., Pedersen, B., \& Stubkjær, K. (1991). Coupling between angled-facet amplifiers and tapered lens-ended fibers. Journal of Lightwave Technology, 9(1), 49-55. https://doi.org/10.1109/50.64922

\section{General rights}

Copyright and moral rights for the publications made accessible in the public portal are retained by the authors and/or other copyright owners and it is a condition of accessing publications that users recognise and abide by the legal requirements associated with these rights.

- Users may download and print one copy of any publication from the public portal for the purpose of private study or research.

- You may not further distribute the material or use it for any profit-making activity or commercial gain

- You may freely distribute the URL identifying the publication in the public portal

If you believe that this document breaches copyright please contact us providing details, and we will remove access to the work immediately and investigate your claim. 


\title{
Coupling Between Angled-Facet Amplifiers and Tapered Lens-Ended Fibers
}

\author{
Zheng Wang, Benny Mikkelsen, Bo Pedersen, Kristian E. Stubkjaer, Member, IEEE, \\ and Dennis S. Olesen, Member, IEEE
}

\begin{abstract}
The coupling between angled-facet amplifiers and tapered lens-ended fibers is investigated theoretically and experimentally. The theoretical investigation is based on a three-dimensional plane wave model which accounts for the phase differences introduced by the angled facets. The coupling is investigated with respect to the beam parameters of the amplifier waveguide and the tapered lens-ended fiber, and also with respect to the fiber position. The excess coupling losses due to the facet angle and due to the variation of the fiber lens radius are investigated theoretically and found to be in good agreement with experimental results. For optimized lens radii the excess loss for a $10^{\circ}$ facet angle is found to be less than $0.5 \mathrm{~dB}$ compared to a normal facet amplifier.
\end{abstract}

\section{INTRODUCTION}

CEMICONDUCTOR laser amplifiers will be employed in Smany types of optical systems if a high fiber-to-fiber gain and a low-gain ripple can be obtained. Obviously, good coupling between the fiber and the amplifier together with low-facet reflectivities is important. It should also be pointed out that a high-input coupling efficiency is important to obtain a low-effective noise figure in the amplifier. In this paper we report on the coupling efficiency between angled-facet amplifiers and optical fibers. Previously, work on coupling to normal facet diodes was published [1]-[4]

The angled-facet amplifier is very attractive due to its inherently low modal reflectivity [5]. However, the angled facet modifies the radiated far-field pattern from the amplifier. Its influence on the coupling efficiency is here investigated as a function of the facet angle and the beam parameters of the amplifier, and also with respect to the position and the direction of the fiber relative to the amplifier. The theoretical predictions are compared with experimental results, and good agreement is obtained.

The paper is organized as follows: the far-field patterns of the angled-facet amplifier and the tapered lens-ended fiber are described in Sections II and III, respectively. Results for the coupling efficiency are given in Section IV, while Section V gives the conclusion.

\section{Far-Field Pattern of Angled-Facet Amplifiers}

In this section, an approximate analysis of the far-field pattern of angled-facet amplifiers will be presented. It is assumed that the waveguide of the amplifier supports only the fundamental modes.

Manuscript received October 13, 1989; revised July 17,1990. This work was supported in part by RACE project 1027 .

The authors are with the Center for Broadband Telecommunications, Electromagnetics Institute, Technical University of Denmark, DK-2800, Lyngby, Denmark.

IEEE Log Number 9040207
Here we will only consider the $\mathrm{TE}_{00}$ mode but expressions for the $\mathrm{TM}_{00}$ mode would be easy to derive. The field distribution inside the waveguide is described by a Gaussian function

$$
E(x, y, z)=\exp \left(-x^{2} / W_{x}^{2}-y^{2} / W_{y}^{2}\right) \cdot \exp \left(-j k_{z} z\right)
$$

where the $x y z$ coordinate system is as shown in Fig. 1(a), $W_{x}$ and $W_{y}$ in (1) are the parameters for the 1 /e beamwidths in the $x$ and in the $y$ directions. $k_{z}$ is the wave number in the $z$ direction. For convenience, the reference plane is now chosen parallel to the facet of the amplifier and taking the phase difference between the different plane wave components into consideration, (1) is transformed into

$$
\begin{aligned}
E\left(x^{\prime}, y^{\prime}, 0\right)= & \exp \left(-x^{\prime 2} / W_{x}^{2}\right) \cdot \exp \left(-y^{\prime 2} \cos ^{2} \theta_{0} / W_{y}^{2}\right) \\
& \cdot \exp \left(-j k_{z} y^{\prime} \sin \theta_{0}\right)
\end{aligned}
$$

where $\theta_{0}$ is the tilt angle as shown in Fig. 1(a).

The field of (2) can be represented as the Fourier transformation of an angular spectrum $F\left(\alpha^{\prime}, \beta^{\prime}\right)$ of plane waves incident at different directions $\left(\alpha^{\prime}, \beta^{\prime}\right)$

$$
\begin{aligned}
F\left(\alpha^{\prime}, \beta^{\prime}\right)= & \frac{\pi W_{x} W_{y} n_{1}^{2}}{\lambda^{2} \cos \theta_{0}} \exp \left(\frac{-\pi^{2} n_{1}^{2} \alpha^{\prime 2} W_{x}^{2}}{\lambda^{2}}\right) \\
& \cdot \exp \left(\frac{-\pi^{2} n_{1}^{2} W_{y}^{2}}{\lambda^{2}}\left(\gamma^{1} \sin \theta_{0}+\beta^{\prime} \cos \theta_{0}\right)^{2}\right) .
\end{aligned}
$$

Here $\alpha^{\prime}, \beta^{\prime}$, and $\gamma^{\prime}$ are the directional cosines of the coordinate system $x^{\prime} y^{\prime} z^{\prime}$ and $\lambda$ is the wavelength of the light. $n_{1}$ is the effective refractive index of the waveguide [6] given by

$$
n_{1}^{2}=\frac{\int_{-\infty}^{+\infty} n^{2}(x) E^{2}(x, y) d x d y}{\int_{-\infty}^{+\infty} E^{2}(x, y) d x d y} .
$$

When a plane wave component incident at $\left(\alpha^{\prime}, \beta^{\prime}\right)$ passes the coating layer both its amplitude and its direction of propagation change. The direction changes according to Snell's law (see Fig. 1(b)), whereas the change in the amplitude is given by the Fresnel transmission and reflection coefficients. Thus, the plane wave spectrum $F_{a}\left(\alpha^{\prime}, \beta^{\prime}\right)$ after the coating is given by [7]

$$
\begin{aligned}
& F_{a}\left(\alpha^{\prime}, \beta^{\prime}\right) \\
& \quad=F\left(\alpha^{\prime}, \beta^{\prime}\right) \frac{t_{12}\left(\alpha^{\prime}, \beta^{\prime}\right) t_{23}\left(\alpha^{\prime}, \beta^{\prime}\right) \exp \left(j B\left(\alpha^{\prime}, \beta^{\prime}\right)\right)}{1+r_{12}\left(\alpha^{\prime}, \beta^{\prime}\right) r_{23}\left(\alpha^{\prime}, \beta^{\prime}\right) \exp \left(j 2 B\left(\alpha^{\prime}, \beta^{\prime}\right)\right)}
\end{aligned}
$$




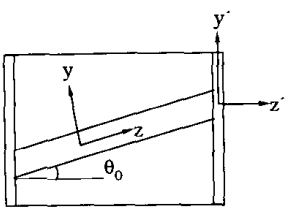

(a)

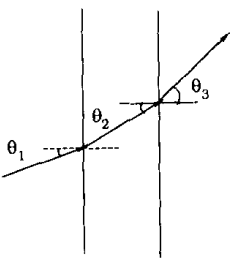

(b)
Fig. 1. (a) Schematic of an angled-facet amplifier and the coordinate systems ( $x y z$ and $\left.x^{\prime} y^{\prime} z^{\prime}\right)$. (b) Schematic of the coating layer.

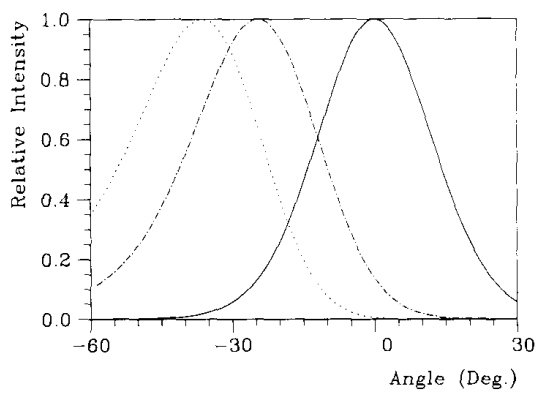

(a)

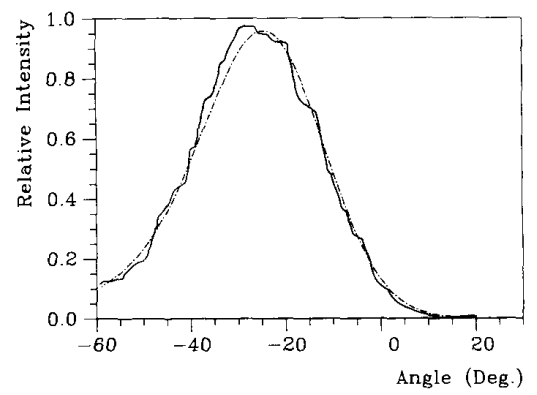

(b)

Fig. 2. (a) Far-field patterns of the $\mathrm{TE}_{00}$ mode in the lateral direction for different facet angle: $\theta_{0}=0^{\circ}\left(\square^{\circ}, 7^{\circ}(\ldots, \cdots,-)\right.$, and $10^{\circ}$ $(\cdots \cdots)$. (b) Numerical $(\cdots \cdots, \cdot)$ and experimental $(-)$ far field pattern of the investigated $7^{\circ}$ angled-facet amplifier.

where $t_{12}\left(\alpha^{\prime}, \beta^{\prime}\right)$ and $r_{12}\left(\alpha^{\prime}, \beta^{\prime}\right)$ are the Fresnel transmission and reflection coefficients between region 1 and region 2 , and $t_{23}\left(\alpha^{\prime}, \beta^{\prime}\right)$ and $r_{23}\left(\alpha^{\prime}, \beta^{\prime}\right)$ are those for region 2 and region 3 while $B$ is given by

$$
B=\frac{2 \pi n_{2}}{\lambda} h \sqrt{1-\alpha^{\prime 2}-\beta^{\prime 2}} .
$$

In (6) $n_{2}$ is the refractive index and $h$ is the thickness of the coating layer.

According to [8], the far-field pattern $S\left(\alpha^{\prime}, \beta^{\prime}\right)$ is expressed as

$$
S\left(\alpha^{\prime}, \beta^{\prime}\right)=C_{1}\left(1-\alpha^{\prime 2}\right)\left|F_{a}\left(\alpha^{\prime}, \beta^{\prime}\right)\right|^{2}
$$

where $C_{1}$ is a constant

We have calculated the far-field pattern of an angled-facet amplifier in the direction parallel to the junction plane for different angles $\theta_{o}$ between the waveguide and the facet normal. As shown in Fig. 2(a) the far-field pattern of the $\mathrm{TE}_{00}$ mode is not Gaussian distributed, but is becoming increasingly asym-

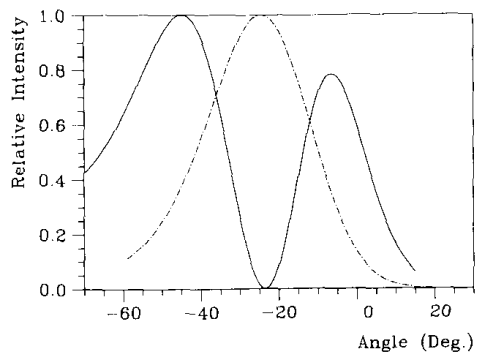

Fig. 3. Far-field distributions for $\mathrm{TE}_{00}$ mode (-...-.- $)$ and $\mathrm{TE}_{01}$ mode (- ) for an angled-facet amplifier with a facet angle of $\theta_{0}=7^{\circ}$.

metric for increasing facet angle $\theta_{0}$. To determine the beam parameters, we have compared the measured far-field pattern with the calculated far-field pattern. Fig. 2(b) shows the comparison, from which, we found the beam parameters of the waveguide mode.

Recently, it has been suggested [9] that the gain for the $T E_{01}$ mode of an angled-facet amplifier has a higher saturation power due to a low confinement factor. We have therefore considered coupling to the $\mathrm{TE}_{01}$ mode. The field for the $\mathrm{TE}_{01}$ mode is expressed as

$$
E(x, y, z)=y \exp \left(-x^{2} / W_{x}^{2}-y^{2} / W_{y}^{2}\right) \cdot \exp \left(-j k_{z} z\right)
$$

and repeating the same steps as described above, we have calculated the far-field pattern for the $\mathrm{TE}_{01}$ mode of angled-facet amplifiers as shown in Fig. 3. The results are in good agreement with the experimental results in [9] and therefore confirm the validity of our plane wave spectrum model. The far field has two peaks at angles of -6.5 and $-45.5^{\circ}$ and approximately $65 \%$ of the energy is emitted in the latter direction. In general, we can only couple one of the peaks into the fiber, and therefore the best coupling efficiency in the case of $\mathrm{TE}_{01}$ operation is 1.8 $\mathrm{dB}$ lower than for the $\mathrm{TE}_{00}$ case. In addition, the higher order modes are the main reason for the gain ripple for angled-facet amplifiers [10], and consequently, a waveguide with cutoff before the first-order mode is considered best.

\section{Far Field of Tapered Lens-Ended Fiber}

In this section, we will discuss the far-field pattern of a tapered lens-ended fiber as shown in Fig. 4. The mode conversion in the taper and the lens is studied with the beam propagation method (BPM) which allows for a numerical calculation of the field. The BPM solves the scalar-wave equation [11] in small propagation steps along the fiber taper axis. In each step the input field is propagated first through a homogeneous medium with an effective refractive index and second through an infinite thin lens correcting for the index variation during the step. It should be added that an analytical solution for the field in the taper section is difficult to obtain.

The tapered lens-ended fibers are fabricated from standard silicon fibers with taper lengths of about $300 \mu \mathrm{m}$ and lens radii of about $15 \mu \mathrm{m}$. The transverse diameter of the fiber taper is linearly changed (see Fig. 4) along the axial direction of the fiber and the optical field distribution in the $\mathrm{AA}_{1}$ plane is taken as a Gaussian function with a flat phase front. The beamwidth $W_{f o}$ is estimated by [12]

$$
W_{f o}=a\left(0.65+\frac{1.619}{V^{3 / 2}}+\frac{2.879}{V^{6}}\right)
$$




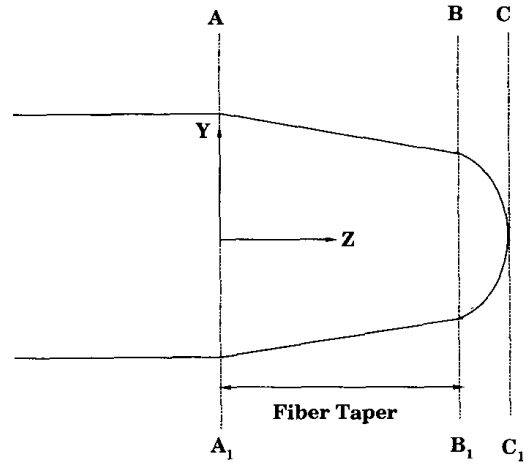

Fig. 4. Schematic of a tapered lens-ended fiber.

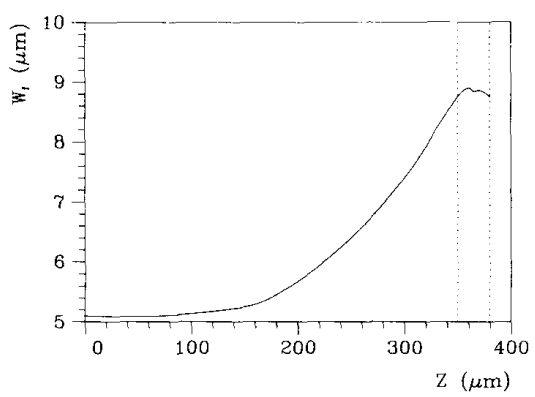

Fig. 5. The $1 / \mathrm{e}$ beamwidth of the local mode of the tapered lens-ended fiber versus the position along the fiber axis.

where $a$ is the radius of the fiber core, and $V$ is given by

$$
V=\left(n_{1 f}^{2}-n_{2 f}^{2}\right) k^{2} a^{2}
$$

$n_{1 f}$ and $n_{2 f}$ are the refractive indexes of the fiber core and the cladding layer. As the optical field propagates from the $\mathrm{AA}_{1}$ plane to the $\mathrm{BB}_{1}$ plane (see Fig. 4), it spreads out and the beamwidth increases along the fiber taper as shown in Fig. 5. Passing through the fiber lens the concave phase front is changed into a convex (see the solid curves in Fig. 6), however, the beamwidth of the field in the $\mathrm{CC}_{1}$ plane is about same as in the $\mathrm{BB}_{1}$ plane.

The far-field pattern is calculated from a Fourier transformation of the field distribution in the $\mathrm{CC}_{1}$ plane [8] as shown in Fig. 7 by the dotted curve. The good agreement with the measured far field given by the solid curve supports the validity

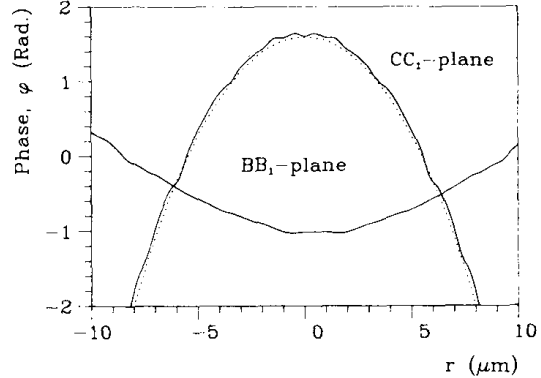

Fig. 6. Phase conversion by the fiber lens, calculated by BPM (- - and the simple method $(\cdots \cdots)$.

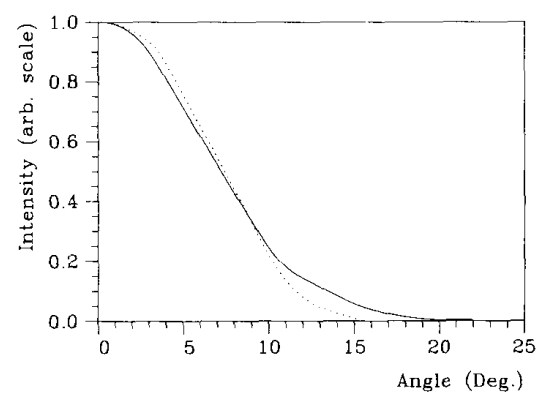

Fig. 7. Calculated $(\cdots \ldots \ldots)$ and measured $(\longrightarrow)$ far-field pattern of the tapered lens-ended fiber.

\section{Coupling Between Amplifier and Fiber}

In this section the coupling efficiency between tapered lensended fibers and angled-facet amplifiers is investigated theoretically and experimentally. The investigation is concerned with the influence of the beam parameters of the tapered lens-ended fiber and of the amplifier, the fiber position, and direction. The excess coupling losses due to the facet angle and due to the variation of the fiber lens radius are also investigated.

\section{ANALYSIS}

The schematic of the coupling from an angled-facet amplifier to a tapered lens-ended fiber is shown in Fig. 8. The reference plane for the analysis is chosen at the tip of the fiber as indicated. The coupling efficiency $K_{1}$ can be expressed by the overlap integral between the fields $E_{a}$ and $E_{f}$ of the amplifier and the fiber taken in the reference plane

$$
K_{1}=\frac{\left|\iint_{-\infty}^{+\infty} E_{a}\left(x_{1}, y_{1}\right) E_{f}^{*}\left(x_{1}, y_{1}\right) d x_{1} d y_{1}\right|^{2}}{\iint_{-\infty}^{+\infty}\left|E_{a}\left(x_{1}, y_{1}\right)\right|^{2} d x_{1} d y_{1} \iint_{-\infty}^{+\infty}\left|E_{f}\left(x_{1}, y_{1}\right)\right|^{2} d x_{1} d y_{1}} .
$$

of the BPM calculation. The $1 / \mathrm{e}$ beamwidth in the $\mathrm{CC}_{1}$ plane is $W_{f}=8.8 \mu \mathrm{m}$.

The BPM requires a long computation time, so for an investigation of the influence of the fiber lens radius on the coupling efficiency we have investigated the possibility of considering the lens as a phase delay only. The dotted curve in Fig. 6 gives the phase distribution which results from this procedure and as can be seen it is in good agreement with the phase distribution resulting from the BPM calculation.
The field distribution of the tapered lens-ended fiber $E_{f}$ is obtained from the BPM calculation as described in Section III. The field distribution $E_{a}\left(P_{0}\right)$ of the angled-facet amplifier in the reference plane, is given by [13]

$$
E_{a}\left(P_{0}\right)=\iint_{S_{r}} h\left(P_{0}, P_{1}\right) E\left(P_{1}\right) d S_{1}
$$

where $E\left(P_{1}\right)$ is the field distribution at the facet as given by (2), $S_{r}$ designates the reference plane, and $h\left(P_{0}, P_{1}\right)$ is given 


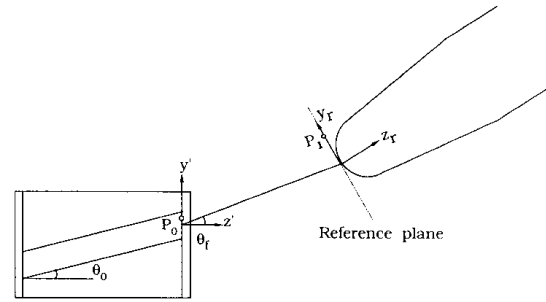

Fig. 8. Schematic of coupling from an angled-facet amplifier to a tapered lens-ended fiber.

by

$$
h\left(P_{0}, P_{1}\right)=\frac{1}{j \lambda} \frac{\exp \left(j k r_{01}\right)}{r_{01}} \cos \left(\vec{n}, \vec{r}_{01}\right)
$$

where $\vec{n}$ is the unit vector in the direction of the facet normal and the vector $\vec{r}_{01}$ is defined by the points $P_{0}$ and $P_{1}$ as shown in Fig. 8. $r_{01}$ is the distance between $P_{0}$ and $P_{1}$.

The coupling efficiency can, however, be calculated more efficiently by using an analogous expression [14], [15]

$$
K_{1}=K_{x 1} K_{y 1}
$$

here $K_{x 1}$ and $K_{y 1}$ are the coupling efficiencies calculated in the coordinate planes $x_{r} z_{r}$ and $y_{r} z_{r}$ (see Fig. 8).

The coupling efficiency estimated by (11) will be modified by the Fresnel reflection at the lens surface to give the coupling efficiency

$$
K=K_{1}+\Delta K
$$

where $\Delta K$, which is due to the Fresnel reflection, is a function of the beam parameter of the amplifier, the lens radius, and the index of the fiber. For lenses with a radius larger than the core diameter of the fiber, the excess coupling loss is approximately $0.4 \mathrm{~dB}[16]$.

\section{Results}

In the calculations we simulated the angled-facet ridge waveguide amplifiers for which good performance has been obtained in our previous experiments [5]. The 1 /e widths $W_{x}$ and $W_{y}$ for the beam of the amplifier are determined from measurements of the far-field pattern. The estimated values for $W_{x}$ and $W_{y}$ are 0.6 and $1.3 \mu \mathrm{m}$, respectively, and the effective refractive index obtained from (4) is 3.28 [17]. As mentioned in Section III the $1 / \mathrm{e}$ width for the beam of the tapered lens-ended fiber in the reference plane is $W_{f}=8.8 \mu \mathrm{m}$.

Fig. 9 gives the coupling efficiency versus the angle $\theta_{f}$ between the fiber and the facet normal of the amplifier. Amplifiers with facets angled at $\theta_{0}=7^{\circ}$ and $\theta_{0}=10^{\circ}$ and fibers with a lens radius of $15 \mu \mathrm{m}$ are considered. For each value of $\theta_{f}$ the distance between the fiber and the amplifier is optimized for maximum coupling efficiency. In the case of an amplifier with a facet angle of $\theta_{0}=7^{\circ}$ the calculated coupling efficiency is $-7.5 \mathrm{~dB}$ in the direction of the facet normal while it can be as high as $-2.7 \mathrm{~dB}$ for $\theta_{f}=-24^{\circ}$. For an amplifier with a $10^{\circ}$ facet angle the highest coupling efficiency is $-2.9 \mathrm{~dB}$ for an angle of $\theta_{f}=-34^{\circ}$. The experimental results obtained from spontaneous emission measurements for the 7 and the $10^{\circ}$ amplifiers are given by circles and squares. The maximum coupling efficiencies are -3.5 and $-3.8 \mathrm{~dB}$ in the two cases. In the experiment, the tapered lens-ended fiber is coupled to one

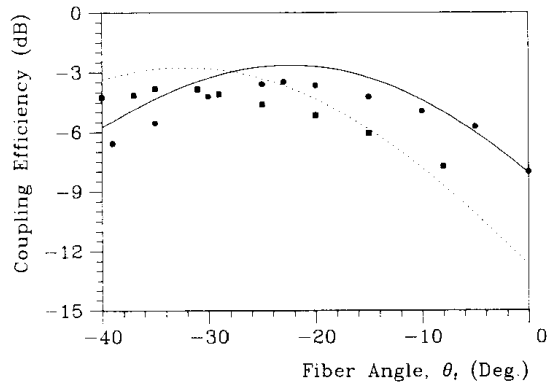

Fig. 9. Coupling efficiency versus the angle $\theta_{f}$ to the facet normal of the tapered lens-ended fiber for $\theta_{0}=7^{\circ}$ (theoretical: — , experimental: $\bullet$ and for $\theta_{0}=10^{\circ}$ (theoretical: $\cdots \cdots$, experimental: $\mathbf{\square}$ ).

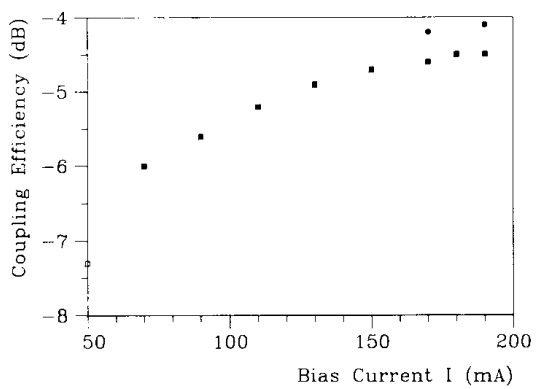

Fig. 10. Experimental results of the coupling efficiency for the spontaneous emission $(\boldsymbol{D})$ and for the signal $(\bullet)$ versus the bias current of the $10^{\circ}$ angled-facet amplifier.

facet of the amplifier, while a broad-area detector which collects all the light is used at the other facet (equal power from both facets). The coupling efficiency measured for the spontaneous emission from the amplifier depends on the bias current of the amplifier, especially at a low current level, as shown in Fig. 10. When the bias current changes from $50 \mathrm{~mA}$ to $150 \mathrm{~mA}$, the coupling efficiency increases approximately $1.5 \mathrm{~dB}$. A further increase of the bias current will not increase the coupling. This current dependence of the coupling efficiency is due to the fact that the amplified spontaneous emission does not exist inside the amplifier as a single well-defined guided mode for low gain. However, for high gain most of the amplified spontaneous emission is guided in the fundamental mode at the output facet. In Fig. 10 we also show the coupling efficiency for the signal (shown as - in Fig. 10), which is measured as follows: a chopped signal is coupled to one facet of the amplifier while a broad-area detector collects all the amplified signal at the other facet. The coupling efficiency can be estimated from comparison of the power measured with the broad-area detector to the power measured when the tapered lens-ended fiber collects the amplified signal. The coupling efficiency for the signal is about $0.5 \mathrm{~dB}$ higher than the coupling efficiency for the spontaneous emission at a high-bias current level. The lower coupling efficiency for spontaneous emission is attributed to chromatic aberration. This can partly explain the difference between the theoretical results and the experimental results in Fig. 9.

We have investigated the excess coupling loss for the $10^{\circ}$ amplifier as a function of the lens radius of the tapered lensended fiber. The solid curve in Fig. 11 gives the theoretical result, which predicts the highest coupling efficiency for a lens 


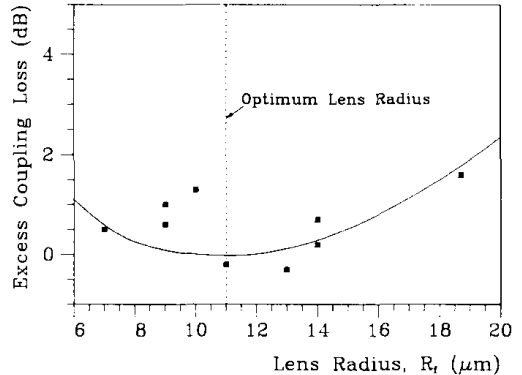

Fig. 11. Theoretical ( $\longrightarrow$ ) and experimental results $(\square)$ for excess coupling loss versus the lens radius of the tapered lens-ended fiber.

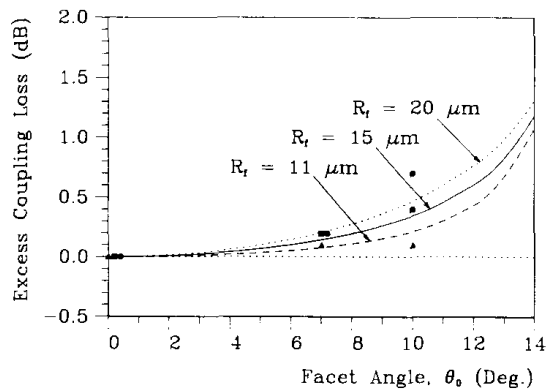

(a)

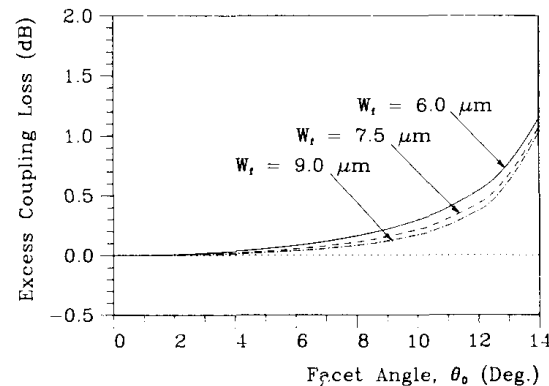

(b)

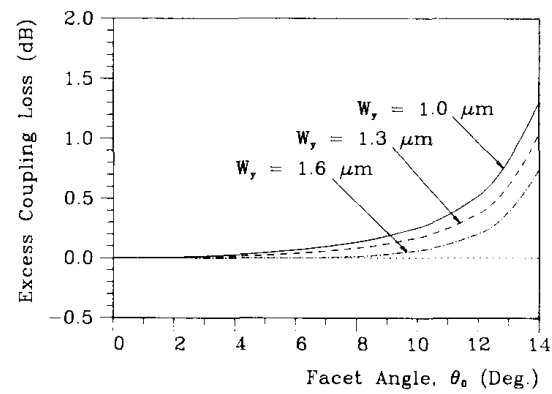

(c)

Fig. 12. (a) The excess coupling loss versus the facet angle of the angledfacet amplifier with the lens radius $R_{f}$ as a parameter, $R_{f}=11 \mu \mathrm{m}$ $(\cdots--), R_{f}=15 \mu \mathrm{m} \mathrm{(-}(-)$, and $R_{f}=20 \mu \mathrm{m}(\cdots)$. (b) The excess coupling loss versus the facet angle of the angled-facet amplifier with $W_{f}$, the 1/e beamwidth of the fiber taper mode in the $\mathrm{CCl}$ plane (see Fig. 4), $W_{f}$, as a parameter, $W_{f}=6 \mu \mathrm{m}(-), W_{f}=7.5 \mu \mathrm{m}(\cdots \ldots . \cdot \cdot)$, and $W_{f}=9 \mu \mathrm{m}(\cdots---)$. (c) The excess coupling loss versus the facet angle of the angled-facet amplifier with the 1/e beamwidth of the amplifier in transverse direction $W_{v}$ as a parameter, $W_{v}=1.0 \mu \mathrm{m}(-), W_{y}=1.3$ $\mu \mathrm{m}(\cdots--)$, and $W_{y}=1.6 \mu \mathrm{m}(-\cdots \cdot \cdots \cdot-)$.

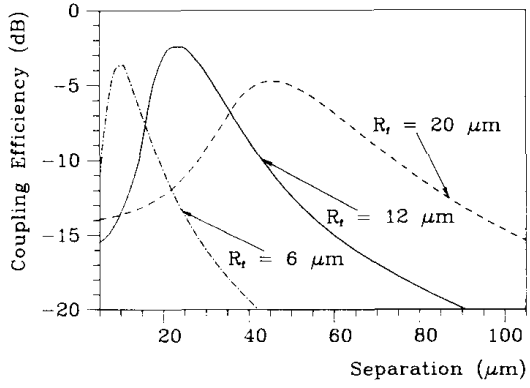

Fig. 13. Coupling efficiency versus the separation between the angled-facet amplifier and a tapered lens-ended fiber with different lens radius. $R_{f}=6$ $\mu \mathrm{m}(-\cdots \cdots \cdot), R_{f}=12 \mu \mathrm{m}(-)$, and $R_{f}=20 \mu \mathrm{m}(\cdots \cdots)$.

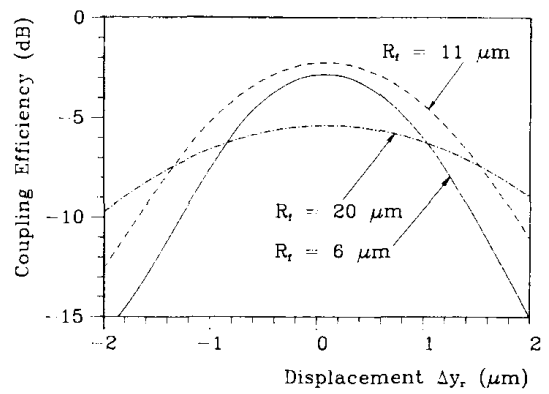

Fig. 14. Coupling efficiency for a $7^{\circ}$ angled-facet amplifier to tapered lensended fibers versus the displacement of the fibers in the $\Delta y_{r}$ direction, with $R_{f}$ as a parameter, $R_{f}=6 \mu \mathrm{m}(--), R_{f}=11 \mu \mathrm{m}(-\cdots)$, and $R_{f}=20$ $\mu \mathrm{m}(-\cdots \cdot \cdots-\cdot)$.

radius of $11 \mu \mathrm{m}$. As seen, the excess coupling loss varies slowly with the lens radius, and for lens radii of 6 and $20 \mu \mathrm{m}$ the excess coupling losses are 1.1 and $2.3 \mathrm{~dB}$, respectively. The open squares give the experimental results which agree with the theoretical results within $1 \mathrm{~dB}$.

The excess coupling due to the angled facet is investigated for different lens radii of the tapered fibers. The theoretical and experimental results are shown in Fig. 12(a) and for a lens radius of $R_{f}=11 \mu \mathrm{m}$ the excess coupling loss can be as low as 0.1 and $0.2 \mathrm{~dB}$ for $\theta_{0}=7$ and $10^{\circ}$, respectively. Similarly, for $R_{f}=20 \mu \mathrm{m}$, the excess coupling loss will be 0.2 and $0.5 \mathrm{~dB}$. The experimental results are in agreement with the numerical results within $0.2 \mathrm{~dB}$. Similarly, Fig. 12(b) and (c) gives the dependences of the excess coupling on facet angle with $W_{f}$ and $W_{y}$ as parameters. As seen, for a lens radius of $10-20 \mu \mathrm{m}$ the excess coupling loss will remain low for facet angles of less than $12^{\circ}$.

The coupling efficiency versus the separation between a $7^{\circ}$ angled-facet amplifier and a tapered lens-ended fiber is shown in Fig. 13, with the fiber in the direction of $\theta_{f}=-24^{\circ}$. The three curves are for $R_{f}=6,12$, and $20 \mu \mathrm{m}$. The coupling efficiency reaches the maximum values for separations of 9,23 , and $44 \mu \mathrm{m}$, respectively. Our results are in qualitative agreement with the experimental results published in [1] for coupling to a laser diode. Especially, our model explains the behavior of the coupling efficiency for a short fiber-amplifier distance.

The coupling efficiency versus the displacement in the $y_{r} \mathrm{di}-$ rection (see Fig. 8) is also investigated. The sensitivity is nearly the same in the $x_{r}$ and the $y_{r}$ directions and as an example Fig. 
14 gives the coupling efficiency versus $\Delta y_{r}$ for the optimum lens radius $R_{f}=11 \mu \mathrm{m}$ as well as for $R_{f}=6$ and $20 \mu \mathrm{m}$. As expected the tolerances increase with increasing lens radius. For the optimum lens radius $R_{f}=11 \mu \mathrm{m}$ a displacement of $2 \mu \mathrm{m}$ causes a decrease in the coupling efficiency of approximately 9 $\mathrm{dB}$, whereas for the larger lens radius of $20 \mu \mathrm{m}$, the decrease in coupling efficiency is only $4.3 \mathrm{~dB}$. Obviously the choice of lens radius offers a trade-off between a high and a stable coupling efficiency.

\section{CONCLUSION}

We have established a theoretical model which allows calculation of the coupling efficiency between an angled-facet amplifier and a tapered lens-ended fiber. The coupling efficiency was investigated theoretically with respect to the beam parameters of the amplifiers and the fibers as well as the lens radii of the fibers and also with respect to the fiber position and directions. Coupling efficiency to amplifiers with facet angles of 7 and $10^{\circ}$ were investigated experimentally, and maximum coupling efficiencies of -3.5 and $-3.8 \mathrm{~dB}$ were obtained in the two cases with the fiber angled at -23.6 and $-34.5^{\circ}$, respectively. The excess coupling losses, due to the facet angle and due to the variation of the fiber lens radius, were also investigated theoretically and experimentally. With an excess coupling loss of less than $0.5 \mathrm{~dB}$ for the $10^{\circ}$ angled amplifier, this structure is considered very attractive for fabrication of traveling wave amplifiers. Furthermore, the coupling sensitivity in the lateral direction was studied theoretically.

\section{ACKNOWLEDGMENT}

The authors would like to thank Dr. A. Collar and G. Henshall of STL, Harlow, England for supplying the amplifiers.

\section{REFERENCES}

[1] B. Hillerich, "Shape analysis and coupling loss of microlens on single-mode fiber tips," Appl. Opt., vol. 27, pp. 3102-3106, 1988.

[2] R. E. Wagner and W. J. Tomlinson, "Coupling efficiency of optics in single-mode fiber components," Appl. Opt., vol. 21, pp. $2671-2678,1982$.

[3] W. B. Joyce and B. C. Deloach, "Alignment of Gaussian beams," Appl. Opt., vol. 23, pp. 4187-4195, 1984.

[4] H. Kuwahara, M. Sasaki, and N. Tokyo, "Efficient coupling from semiconductor lasers into single-mode fibers with tapered hemispherical ends," Appl. Opt., vol. 19, pp. 2578-2583, 1980.

[5] A. J. Collar et al., "Fabrication and performance of $\lambda=1.5 \mu \mathrm{m}$ angled facet laser amplifiers,"' in Tech. Dig. 11th IEEE Int. Semiconductor Laser Conf. (Boston, MA), 1989, Postdeadline paper 6.

[6] C. Vassallo, "Rigorous and approximate calculation of antireflection layer parameters for traveling wave diode laser amplifiers,"' Electron. Lett., vol. 21, pp. 333-334, 1985.

[7] D. R. Kaplan and P. P. Deimel, "Exact calculation of the reflection coefficient for coated optical waveguide devices,' 'Bell Syst. Tech. J., pp. 857-877, 1984.

[8] R. H. Clark and J. Brown, Diffraction Theory and Antennae. New York: Wiley, 1980.

[9] J. Salzman, R. J. Hawkins, C. E. Zah, S. Menocal, and T. P. Lee, "The tilted waveguide semiconductor laser amplifiers," $J$. Appl. Phys., vol. 64, pp. 2240-2242, 1988.

[10] C. Vasallo, "Gain ripple minimisation and higher order modes in semiconductor optical amplifiers," Electron. Lett., vol. 24, pp. 798-790, 1988

[11] J. Van Roeg, J. Van der Donh, and P. E. Lagasse, "Beam-propagation method: Analysis and assessment," J. Opt. Soc. Amer., vol. 71 , no. 7 , pp. $803-810,1981$.
[12] D. Marcuse, "Loss analysis of single-mode fiber splices," Bell Syst. Tech. J., pp. 579-582, 1977.

[13] J. W. Goodman, Introduction to Fourier Optics. San Fransisco, CA: McGraw-Hill.

[14] J. M. Hammer and C. C. Neil, "Adjustable modules for highpower (over $7.5 \mathrm{~mW}$ ) coupling of diode lasers to single-mode fibers," J. Lightwave Technol., vol. LT-1, pp. 485-489, 1983.

[15] J. I. Sakai and T. Kimura, "Design of miniature lens for semiconductor laser to single-mode fiber coupling," IEEE J. Quantum Electron., vol. QE-16, pp. 1059-1067, 1980.

[16] I. W. Marshall, "Low loss coupling between semiconductor lasers and single-mode fibers using tapered lens-ended fibers, " $\mathrm{Br}$. Telecom. Tech. J., vol. 4, pp. 114-121, 1986.

[17] Z. Wang, B. Mikkelsen, K. E. Stubkjaer, and D. S. Olesen, "Single layer coating for an angled facet amplifier," Electron. Lett., vol. 25, pp. 1139-1141, 1989.

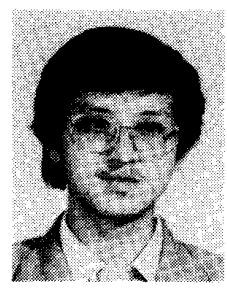

Zheng Wang was born on October 7, 1962 in Changchun, China. He received the B.S. degree in 1984 from the Department of Physics, Jilin University, Changchun. He is currently working toward the Ph.D. degree from the Electromagnetics Institute Technical University of Denmark. Before coming to Denmark, he was a Ph.D. student in the Department of Electronics Science, Jilin University, where he worked on the design and fabrication of semiconductor lasers and laser arrays.

Since December, 1987, he has been with the Electromagnetics Institute Technical University of Denmark. His recent research is on semiconductor laser amplifiers and their applications.

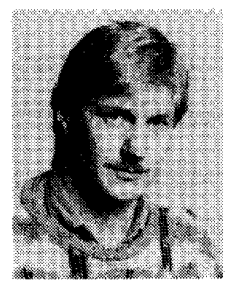

Benny Mikkelsen was born in Sdr. Nissum, Denmark, in 1960 . He received the M.Sc. degree from the Technical University of Denmark, Copenhagen, in 1987. He is currently working toward a Ph.D. at the Electromagnetics Institute. His field of interest is optical communication with emphasis on optical amplifiers

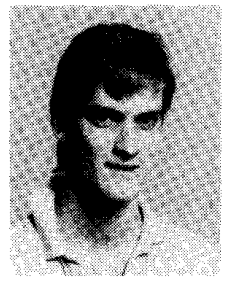

Bo Pedersen was born in Roskilde, Denmark, on October 8, 1965. In August 1989 he re ceived the M.Sc. degree in electrical engineering from the Electromagnetics Institute, Technical University of Denmark. In his Master thesis project he developed a three-dimensional BPM-model for the lens-ended fiber tapers. On February 1, 1990 he started on his $\mathrm{Ph}$.D. on active optical waveguides at the Electromagnetics Institute. 


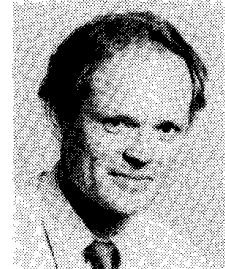

Kristian E. Stubkjaer (S'76-M'81) was born in Arhus, Denmark, in 1953. He received the M.Sc. and $\mathrm{Ph} . \mathrm{D}$. degrees from the Technical University of Denmark, Copenhagen, in 1977 and 1981 , respectively.

From 1979 to 1981 he studied at the Tokyo Institute of Technology, Tokyo, Japan, with a scholarship from the Japanese Government. From 1981 to 1982 he was drafted for military service at the Danish Defence Rescarch Establishment in Copenhagen. From 1782 to 1983 he was a Visiting Scientist at the IBM T. J. Watson Research Center Yorktown Heights, NY. He is now an Associate Professor at the Electromagnetics Institute, Technical University of Denmark, Lyngby, Denmark, where he is working in the field of optical communication. From June 1985 until Feb. 1990 he has been Director of the Electromagnetics Institute.

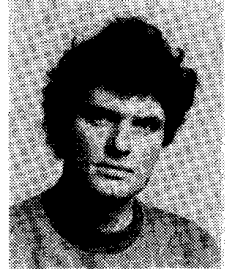

Dennis S. Olesen (M'89) was born in Copenhagen, Denmark in May, 1960 . He received the M.S. degree in electronics engineering from the Technical University of Denmark, Lyngby, Denmark, in 1988.

From 1988 to 1990 he was at the Center for Broadband Telecommunications at the Technical University of Denmark, where he was working with nonlinear properties and optical bistability in semiconductor laser amplifiers. In 1990 he joined NKT Research Center, Brønby, Denmark, where he is working with fiber optical amplifiers 